\title{
Protesta social y espacio público en tiempos del neoliberalismo autoritario en América Latina. Entre la represión y la regulación
}

\author{
Social protest and public space in times of authoritarian neoliberalism in Latin \\ America. Between repression and regulation
}

Recibido: noviembre 2020

Aceptado: agosto 2021

\section{Resumen}

El capitalismo actual se caracteriza por desdeñar los mecanismos de negociación o de cooptación política para enfrentar a los grupos disidentes que cuestionan las políticas económicas implementadas. En el presente trabajo se analizarán algunas de las formas represivas que imponen ciertos Estados latinoamericanos a partir del concepto de neoliberalismo autoritario, en particular, de la restricción del uso del espacio público como arena de protesta por los efectos de las políticas de ajuste. Para ello se toman los casos de México, Colombia y Chile, como países representativos con gobiernos que implementan políticas económicas neoliberales. El objetivo de este artículo es aportar evidencias del giro autoritario de los gobiernos de estas naciones, los cuales, se han expresado en la represión de colectivos sociales, así como una estrategia de acotar el espacio público a través de andamiajes legales.

\section{Palabras Claves:}

espacio público; protesta; neoliberalismo autoritario

\author{
Jesús Bojórquez Luque ${ }^{1}$
}

Manuel Ángeles Villa ${ }^{2}$

\begin{abstract}
Current capitalism is characterized by disregarding the mechanisms of negotiation or engage in political cooptation to confront dissident groups that question the economic policies implemented. In this paper, we will analyze some of the repressive forms imposed by certain Latin American states based on the concept of authoritarian neoliberalism, in particular, the restriction of the use of public space as an arena for protesting the effects of neoliberal adjustment policies. The cases of Mexico, Colombia and Chile are taken as representative of countries whose governments have implemented neoliberal economic policies. The objective of this article is to provide evidence of the authoritarian turn of the governments of these nations, which has resulted in the repression of social groups, as well as constituting a strategy to limit public space by enacting restrictive legislation.
\end{abstract}

\section{Keywords:}

public space; protest; authoritarian neoliberalism

\footnotetext{
${ }^{1}$ Nacionalidad: mexicano; adscripción: Universidad Autónoma de Baja California Sur, correo: bojorquez@uabcs.mx

2 Nacionalidad: mexicano; adscripción: Universidad Autónoma de Baja california Sur. Autor de correspondencia; correo: manan@uabcs.mx
} 


\section{INTRODUCCIÓN}

Para los antiguos griegos el ágora era el espacio público más significativo de la ciudad-Estado: en ella se creaba ciudadanía; así mismo, "era un espacio de vida, encuentros, rituales, transacciones comerciales y debates políticos, que cumplía una triple función: política, económica y religiosa" (Mirón 2014, p. 24). El ágora no sólo tenía importancia desde el punto de vista de la vida democrática, sino también cumplía con otras funciones, como ser centro de comercio y transacciones económicas de diversa índole, pero sobre todo, de ambientes de socialización a partir de juegos, festivales, rituales y acontecimientos religiosos (Mirón, 2014).

En la época medieval, a partir de la dominación de la iglesia, los espacios públicos más importantes fueron los templos, de manera especial la catedral, la cual tuvo funciones no sólo desde el punto de vista religioso, sino de relaciones sociales y festividades (Baigorri, 1995). Fue hasta en los tiempos renacentistas cuando la plaza, fue el espacio público más importante en Europa, lugar de intercambios económicos, sobre todo de alimentos, así como los de tipo social (Sato, 2012).

En tiempos de la industrialización, con una burguesíaempoderada, seornamentaronlasciudades, con parques, jardines, monumentos e instituciones sociales como escuelas, hospitales, cárceles, etc. A su vez, se dio el desarrollo de actividades de ocio, en las cuales se generaban condiciones de sociabilidad de los diferentes grupos humanos que disfrutaban del teatro, los cafés y las tabernas (Gamboa, 2003). En esta evolución del sistema capitalista y en el llamado Estado Benefactor, construido como respuesta a la Gran Depresión de los años treinta del S. XX, los colectivos sociales, como obreros, campesinos y organizaciones populares luchaban por ampliar sus derechos (Ramírez, 2014), siendo la calle y las plazas públicas los espacios de lucha más importantes para visibilizar sus demandas.

En la medida que el capitalismo entró a su etapa neoliberal, las políticas de ajuste económico ideadas para reducir las conquistas de las clases medias y trabajadoras de ese antiguo Estado benefactor, han dado pie a una serie de manifestaciones de organizaciones sindicales y ciudadanas que luchan contra las políticas de precarización. Si bien el espacio público como elemento central de convivencia ciudadana ha tendido a su privatización y control por medio de dispositivos de seguridad, siguen siendo la plaza central y las calles, los lugares simbólicos de la protesta social. En virtud de la poca disposición de los gobiernos neoliberales de negociar y dialogar, al imponer una visión económica y social que renuncia a la posibilidad de tomar en cuenta a la mayoría de la población, el Estado y las élites responden con represión o con leyes regulatorias del espacio público y de las protestas sociales.

El presente trabajo tiene el propósito de analizar los efectos del neoliberalismo autoritario de nuestros días sobre la libertad de expresión, ante la insatisfacción de la población por las políticas económicas enmarcadas en el modelo neoliberal, descontento que se manifiesta en la protesta popular en el espacio público urbano. Utilizando una metodología cualitativa en estudio de casos múltiples de carácter descriptivo ilustrativo, nos enfocamos en los casos de México, Colombia y Chile, exponiendo las formas en que los gobiernos de corte neoliberal han intentado criminalizar la protesta pública, construyendo andamiajes legales que buscan la limitación, cuando no prohibición, de la manifestación popular, acercándose en ocasiones a la situación del estado de excepción (Ong, 2006).

El desarrollo del trabajo está conformado por cinco apartados. En el primero, se hace un análisis de la protesta social como herramienta de la ciudadanía para expresar sus disensos con las políticas públicas. En el segundo apartado, se analiza el concepto de espacio público y la importancia que tiene este elemento en la democracia y la generación de ciudadanía que fortalece la participación política de la sociedad. En la tercera sección, se desarrolla el concepto central del análisis, el llamado neoliberalismo autoritario, el cual proviene de la teoría crítica marxista y se emplea para catalogar al rasgo característico del capitalismo en su etapa actual, donde dominan las políticas públicas que buscan robustecer la economía globalizadora en aras de la competitividad, desmantelando los residuos del Estado benefactor y vulnerando los derechos de los colectivos sociales. En el cuarto, se establecen los criterios metodológicos para la realización del estudio. En el quinto apartado, se hace el análisis y discusión de resultados sobre la protesta social en el espacio público de los países analizados, las formas represivas en que han incurrido los regímenes neoliberales y los andamiajes legales o intentos de imposición de leyes para acotar 
la protesta pública en los espacios públicos urbanos. Al final se hace una reflexión acerca de la situación de los países estudiados a partir de las libertades socavadas por el control social a partir del uso de la fuerza y medios legales que tratan de inhibir la protesta social en el entramado urbano.

\section{PROTESTA SOCIAL}

Como recurso de la población para dar a conocer sus desacuerdos con los gobiernos o las políticas públicas implementadas por los Estados, la protesta social ocurre de manera tradicional en un espacio geográfico dado, por lo que su estudio nos puede dar pistas para entender estos fenómenos. En el caso de América Latina, de acuerdo con Calderón (2012), la mayoría de las protestas sociales fueron en ciudades capitales, lo que subraya la importancia para los grupos demandantes del escenario urbano como caja de resonancia para dar a conocer sus demandas, pues es ahí donde se concentran los medios, las instituciones políticas y los grupos económicos.

En tiempos del capitalismo neoliberal y en medio de sus diversas crisis financieras, ha sido frecuente la imposición de políticas de ajuste que han sido tomadas como dogma, por lo que ha habido una tendencia a reforzar los aparatos represores de Estado para contener el descontento popular. Estas protestas, que han tenido el objetivo de buscar dar marcha atrás a las políticas de austeridad, la privatización de los activos públicos y la mercantilización de los comunes, se han presentado en diversas naciones.

En el caso de Francia, durante las postrimerías de 2010, se suscitaron una serie de huelgas ciudadanas y movilizaciones de trabajadores derivadas de las reformas impulsadas por el presidenteNicolás Sarkozyalsistemadepensiones, que buscaba aumentar la edad jubilatoria a dos años más (Jiménez, 2010; Calderón, 2012). Lo mismo pasó en Irlanda, donde se dieron masivas concentraciones, impulsadas por los sindicatos, para expresar el descontento popular ante las políticas de austeridad del gobierno derivadas de la crisis financiera (Calderón, 2012). En Italia, en diversas ciudades del país, miles de manifestantes tomaron las calles para manifestarse en contra de las políticas económicas del presidente Silvio Berlusconi, que perjudicaban primordialmente a la clase trabajadora (Calderón, 2012); en Portugal, el plan de austeridad del gobierno fue rechazado por la oposición, pues planteaba un recorte a las políticas sociales, y las movilizaciones sindicales paralizaron todo el país (La Jornada, 2010). En Inglaterra, el proceso de privatización educativa se aceleró con el aumento sustantivo a las colegiaturas universitarias, llevándose a cabo violentas protestas $(B B C, 2010)$. En Grecia, se suscitaron continuas huelgas y movilizaciones ciudadanas derivadas de las políticas de austeridad a las que fueron sometidos los ciudadanos bajo los dictados de la Unión Europea y el Fondo Monetario Internacional (Calderón, 2012). En España, en 2011, estalló el llamado movimiento de los Indignados, cuando los jóvenes tomaron las plazas ante la crisis económica y política que aquejaba al país, siendo ellos mismos - los jóvenes - el sector más vulnerable, por lo que demandaban una democracia real y no la de los políticos tradicionales y los banqueros (Salinas, 2015). En Turquía, en 2013, inician una serie de disturbios en la ciudad de Estambul como fruto de las protestas de un grupo ecologista por las políticas neoliberales urbanas, en concreto para salvar el Parque Taksim Gezi, uno de los pocos espacios verdes de la ciudad (CNN, 2013), el cual se iba a transformar en un centro comercial, siendo estos reprimidos por el gobierno turco de manera violenta, lo que dio pie al inicio de un movimiento masivo en contra del régimen de Recep Tayip Erdogan, donde las redes sociales fueron importante en la convocatoria de los grupos de protesta (Hutchinson, 2013).

A principios de 2011, África del norte, concretamente los países de Marruecos, Argelia, Libia, Túnez y Egipto, estuvo inmersa en procesos de revuelta social en contra de los regímenes autoritarios (Priego, 2011). Conocida como la Revolución del Facebook (Barón, 2015), dichos eventos iniciaron en Túnez ante la inmolación de un vendedor ambulante en protesta por su desalojo por la policía, lo que trajo como consecuencia una serie de protestas en contra del régimen autoritario de Zine El Abidine Ben Ali (Turner, 2012), la difusión de los eventos en las redes sociales influenció en los movimientos de protesta en los demás países del norte africano.

América Latina no ha estado al margen de las tensiones originadas por las políticas económicas de ajuste neoliberal, las cuales han provocado grandes protestas y movilizaciones de grupos sociales (Taddei, 2002) que han sido contestadas con legislaciones para regular la protesta pública, 
reforzamiento de los aparatos policiacos, así como la represión como forma de contención social, violentando el espacio público como lugar para la acción social democrática. Acá se ha manifestado una tendencia a criminalizar la protesta social, derecho humano fundamental que busca defender otros derechos. En este marco de restricción del derecho a la protesta, se ha utilizado el uso excesivo de la fuerza pública, además de la regulación de las movilizaciones y manifestaciones de los colectivos en lucha (Centro de Estudios Legales y Sociales [CELS], 2016).

El CELS (2016), enumera algunas de las manifestaciones recientes en Latinoamérica, que encontraron como respuesta del Estado, la represión: estudiantes chilenos en exigencia de la gratuidad de la educación; manifestaciones campesinas en Colombia en medio de la neoliberalización del agro; el magisterio mexicano que lucha contra una reforma educativa que pretende precarizar el empleo docente y privatizar la educación; protestas en Argentina por la precarización de la vida laboral; protestas en contra el extractivismo minero en Perú; manifestaciones por demandas agrarias de reparto agrario en Paraguay; manifestaciones políticas opositoras en Venezuela; y, protestas masivas en Brasil en contra de la canalización de recursos públicos para materialización del mundial de fútbol.

\section{ESPACIO PÚBLICO COMO ELEMENTO DE LA DEMOCRACIA}

Existen dos acepciones de espacio público. La primera tiene que ver con una cuestión comunicativa que fue estudiada por Habermas en términos de la llamada esfera pública, que es donde se manifiestan los diversos actores para dar a conocer sus puntos de vista a través de la llamada opinión pública, característica inherente del juego democrático (Ricart y Remesar, 2013). La idea es que la sociedad civil busca su fortalecimiento a partir de la participación en la discusión de la agenda pública a través de los medios de comunicación o las formas discursivas. El segundo significado, el que nos ocupa, se trata de un activo físico de la ciudad que funge como lugar de reunión de la gente sin tomar en cuenta género o condición socioeconómica. Por ello, tiene una sobresaliente dimensión social y cultural, pues es aquí donde se manifiesta la ciudadanía en términos de su interacción, de recreación o de la libre manifestación de ideas (Borja, 2018). Por naturaleza, la ciudad es un gran espacio público, punto de confluencia de la ciudadanía en busca de ejercer sus derechos ciudadanos, pero depende de sus habitantes asegurar su vigorosidad, de apropiarse de él, de evadir su abandono, de su lucha contra su privatización (Borja, 2011).

La importancia del espacio público para la democracia se sustenta en que es un escenario natural para dar a conocer el pensamiento, los puntos de vista de la sociedad. Por ello es importante involucrarse en su sostenimiento, en la exigencia de su equipamiento, pues dichos espacios son nichos para la expresión ciudadana. Las plazas, las calles, los edificios públicos, son sitios para la manifestación de colectivos de distintas clases sociales que buscan el reconocimiento a sus demandas y formas de concebir el mundo (Páramo y Burbano, 2014). Además su uso, con su consecuente apropiación abona a los sentimientos de identidad, interacción social, y sobre todo, en el caso de las plazas, aumenta la idea de barrio como parte de su zona de representación (Segovia, 2005). Visto desde el entramado urbano de la ciudad, el espacio público es el elemento principal para la conformación de la cultura urbana y la ciudadanía (Berroeta y Vidal, 2012).

En términos jurídicos, el espacio público se encuentra sujeto a una reglamentación por parte de las entidades gubernamentales, pues estas deben encargarse de administrarlo, de tenerlo en óptimas condiciones, así como garantizar el libre acceso a la ciudadanía (Bojórquez, Ángeles y Gámez, 2019). Sin embargo, conforme se ha consolidado el modelo neoliberal, el espacio público se ha puesto en peligro, se ha constreñido. Se observa una fuerte tendencia a su privatización (Monreal, 2016) o a ser invadido por el panoptismo tecnológico como forma de control social, para contener las formas indeseables que el modelo económico rechaza (Bojórquez, Ángeles y Gámez, 2016).

De acuerdo con Janoschka y Sequera (2012), un rasgo distintivo del urbanismo neoliberal es el establecimiento de reglas y acotaciones al uso del espacio con el propósito de, en su momento, conferirle un valor de cambio para que predomine sobre su valor de uso, todo dentro de la lógica utilitarista. De esta forma, un espacio público que una vez fue lugar de debate crítico de las ideas y diálogo entre clases sociales, en el contexto neoliberal, se ha perfilado en términos de la ganancia en forma de malls, orientados a la obtención de mercancías y el fomento al 
consumismo (Salcedo, 2002) en medio de un ambiente securitario. De ahí que para la gran mayoría su valor de uso está por encima de cualquier valor de cambio (Lefebvre, 1970) que segrega, reduce y privatiza lo que por naturaleza le es inherente al ser humano en términos del derecho a la ciudad, a su goce y disfrute, a su uso ingenioso y crítico.

$\mathrm{Si}$ el espacio público se relaciona con la construcción de ciudadanía, el conflicto en sí mismo debe ser su naturaleza, pues es ahí donde hacen escena las problemáticas generadas en las relaciones de poder Estado-sociedad. Ahí confluyen amplias capas sociales que luchan por no ser marginadas y segregadas en lo político, económico, social y cultural, que rechazan su precarización y que buscan la visibilización de sus demandas planteando su alteridad (Fernández, 2011).

Empero, como se ha dicho, en los tiempos actuales de la neoliberalización se ha fortalecido un Estado dogmático, promotor del libre mercado, que favorece a las grandes corporaciones financieras, incrementando la inversión en fuerzas represoras que combatan toda forma de protesta hacia el modelo, creando andamiajes legales para controlar los estallidos de descontento social mediante acotación o la represión.

\section{NEOLIBERALISMO AUTORITARIO}

Hay quienes ligan de manera natural la relación entre capitalismo y democracia; desde esa óptica, Fukuyama (1994) sostiene que ambos son elementos que coexisten y que, más aún, en los últimos tiempos ha tendido a fortalecerse dicha unión. Desde una perspectiva crítica, sin embargo, tal afirmación está en entre dicho al observarse como el capitalismo neoliberal ha prohijado, como parte misma de las exigencias de quienes lideran las grandes corporaciones que lo conforman, regímenes oligárquicos y dictatoriales, como Chile en la época pinochetista o las monarquías árabes ricas en petróleo en la actualidad.

Si bien, desde antes de la emergencia de neoliberalismo, la represión se había dado, sobretodo en el marco de la llamada guerra fría y la contención del avance de los grupos que pugnaban por la implementación del socialismo, también se establecieron mecanismos de negociación y cooptación que derivó en la cesión de derechos y beneficios para las clases trabajadoras y la clase media. En la actualidad, diferentes teóricos han sostenido que los mecanismos de control y represión se han tendido a fortalecer en tiempos del capitalismo neoliberal en aras de contener la protesta social derivada de las políticas de ajustes, que han propiciado un marco de incertidumbre entre las clases medias y trabajadoras al desmantelarse los rasgos del antiguo Estado benefactor. Bruff (2014) señala que estamos en medio de la manifestación de un neoliberalismo autoritario, en el que los Estados pierden su esencia democrática al consolidarse regímenes, que a partir de modificaciones o reformas legales buscan inmunizarse ante los conflictos sociales y políticos que se dan a partir de sus políticas públicas. De manera contradictoria, son estas medidas de carácter en extremo impopular las que de manera creciente han dado como resultado la potencialización de una serie de luchas populares y demandas que tienen que ver con el aislamiento o poca disposición al diálogo de los gobiernos con grandes sectores de la población.

La respuesta a estas manifestaciones se da mediante una mayor vigilancia e incremento en la coerción, ambos con el objeto de conservar los valores que entrañan el modelo económico y su culto al consumismo que beneficia a las grandes corporaciones tanto económicas como financieras, dominadas por las élites de los países desarrollados, en concordancia con las élites de los países subdesarrollados (Jessop, 2019), quienes provocan procesos desiguales en la apropiación de la generación de riqueza (Bruff y Tansel 2019b), promoviendo la economía improductiva a través de la especulación financiera (Tansel, 2018).

En el neoliberalismo autoritario, se consolidada la llamada sociedad disciplinaria, donde no sólo reina el panóptico electrónico (Bojórquez Luque, Ángeles y Gámez, 2016, 2020), sino que se busca controlar a las poblaciones mediante la coerción, menospreciando las estrategias de negociación y del consentimiento en favor de la cooptación. Tal actitud pretende justificarse por los supuestos beneficios a la economía de las políticas de libre mercado, argumentándose sobre todo la creación y protección de puestos laborales. En consecuencia, se entra a una dinámica de reestructuración de los sitios sociales, sean estos el hogar, los lugares de trabajo o los espacios urbanos, entre ellos el espacio público. A tal efecto, se promueve un marco normativo donde se da una mayor centralización del poder estatal, acotándose la participación popular en la toma de decisiones y fortaleciéndose los aparatos represivos del Estado 
(Bruff y Tansel, 2019a; Bojórquez, Ángeles y Gámez, 2020). El modelo económico neoliberal se fundamenta en la privatización del espacio a través del proceso que David Harvey (2005) nombró como la "acumulación por despojo", en el que, de manera similar a la acumulación originaria a la que Marx hizo alusión en El Capital, pasan a manos privadas los activos comunes, tales como las riquezas del subsuelo, la propiedad comunal, los sistemas educativos, de salud, de servicios público, de pensiones, etc. (Bojórquez y Ángeles, 2014; Bojórquez, 2016; Bojórquez y Ángeles, 2019).

Aunque el neoliberalismo autoritario es el reforzamiento de las prácticas represoras gubernamentales, también de manera contradictoria tiende a perfeccionar y mejorar las tácticas de resistencia de la población afectada, que busca establecer un mundo mejor, combatiendo la precariedad e incertidumbre que significa la política económica y social del capitalismo neoliberal. Para ello, los colectivos se manifiestan de diferentes formas, se congregan en la plaza púbica, diseñan sus convocatorias en las redes sociales e irrumpen en el espacio público urbano con todo su vigor (Bruff y Tansel, 2019).

\section{METODOLOGÍA}

En el presente estudio se utiliza el método cualitativo basado en el estudio de casos múltiples, de corte descriptivo e ilustrativo (Díaz, Mendoza y Porras, 2011), el cual tiene como propósito dar cuenta de la realidad a partir de ejemplos de diversos tópicos, entre ellos de tipo político (Morra y Friedlander, 2001). Dicha metodología se basa en hacer acopio de datos, muy común en las investigaciones de corte cualitativo, con el fin de tener evidencia empírica del fenómeno contemporáneo a estudiar para dilucidar los límites de este y su contexto (Castro, 2010).

La selección de los casos se dio en términos de una muestra no probabilística e intencional, por ser considerados como típicos en la problemática abordada, llamada también como muestra teórica, cuyo objetivo son los casos en los que se pueda replicar la teoría central (Martínez Carazo, 2006).

En el caso del presente trabajo, el concepto central es Neoliberalismo Autoritario, el cual tiene un carácter estructural que se puede aplicar a diferentes fenómenos muy propios del capitalismo actual, en concreto se plantea como este modelo económico neoliberal ha tendido a reforzar las formas autoritarias en la aplicación de políticas públicas sin tomar en cuenta a la mayoría de la población, lo que trae consigo la criminalización y represión de los colectivos sociales que difieren de dichas políticas públicas y las expresan en el espacio público urbano. La selección de los casos se dio a partir de tomar casos representativos como los regímenes de México, Colombia y Chile que han consolidado el modelo neoliberal, con andamiajes legales que acotan la participación social y han sido puestos a prueba por una ciudadanía que ha cuestionado las políticas de ajuste en materia económica en dichas naciones.

\section{DISCUSIÓN Y RESULTADOS}

Se muestra el análisis de la evidencia empírica en los resultados de la investigación de los tres países analizados, a partir del fenómeno de la protesta social en América Latina, en concreto de México, Colombia y Chile, aterrizando a las formas represivas y regulatorias de los regímenes de dichos países ante la protesta social en el espacio público.

\subsection{Protesta social en América Latina}

El autoritarismo mina a la democracia y sobre todo en países donde se presenta debilidad institucional, donde no se presentan mecanismos de consulta para que las personas decidan sobre políticas públicas prioritarias, por lo que hay una imposición o verticalidad en su ejecución (Sánchez, 2018). El autoritarismo, representa un riesgo para los sectores inconformes que salen a la plaza pública a exigir el cambio de política gubernamental. Aunque dicho régimen ha llegado al poder en base a una serie de instituciones representativas, elecciones con participación de diversas fuerzas políticas, ya en el poder, los actores autoritarios dejan al margen a fuerzas políticas representativas, llevando a cabo maniobras para minar la autonomía de organismos del Estado que deberían consolidar el equilibrio de poderes y evitar el abuso del ejercicio de la función pública por parte de la élite política. Escudándose en un discurso en torno al Estado de derecho, se producen una serie de limitantes en las libertades y derechos ciudadanos que elimina los consensos sociales como forma de gobierno (Szmolka, 2011). En los últimos 
tiempos, las crisis económicas muy presentes en la era neoliberal, han generado protestas de la población por las políticas de ajuste, encontrado como respuesta una serie estrategias represivas, descartando en todo momento el diálogo como solución a la crispación social (Juego, 2018).

En ese tenor, América Latina, ha estado sujeto a políticas de ajuste neoliberal en el cual se ha dado primacía al libre mercado, fomentándose una flexibilidad laboral, salarios bajos y trabajadores sin seguridad social que les garantice salud, educación y pensiones. Aunado a eso, se da un proceso de privatización de los comunes como agua, suelo, riquezas del subsuelo, bosques, playas y la imposición de megaproyectos que vulneran el tejido social, las costumbres y tradiciones en territorios sagrados.

\subsubsection{Caso mexicano}

México entró en la ortodoxia neoliberal a principios de los años ochenta con el gobierno de Miguel de la Madrid Hurtado (1982-1988), tras ese gobierno que inició el proceso de apertura económica (Bojórquez y Ángeles, 2014), se profundizaron las políticas privatizadoras con el gobierno de Carlos Salinas de Gortari (1988-1994) y Ernesto Zedillo Ponce de León (1994-2000), todos del Partido Revolucionarios Institucional (PRI). En el año 2000 se da la alternancia política, aunque se siguió aplicando el modelo neoliberal con los gobiernos emanados del Partido Acción Nacional (PAN), encabezados por Vicente Fox Quesada (VFQ) y Felipe Calderón Hinojosa $(\mathrm{FCH})$. Este este último, estableció la llamada guerra contra las drogas, estrategia que cobró miles de víctimas, las cuales el gobierno calificó como "daños colaterales". De igual manera, el gobierno de $\mathrm{FCH}$ apoyado por el entonces gobierno del Estado de México encabezado en su momento por Enrique Peña Nieto (EPN), decide reprimir a habitantes de San Salvador Atenco, los cuales se habían opuesto a que el gobierno de VFQ construyera el Aeropuerto Internacional de la Ciudad de México en la zona de Texcoco, además de articularse con otros movimientos realizando actos de solidaridad. En la represión a los campesinos de Atenco fueron encarcelados los principales líderes, ancianos y mujeres, varias de las cuales, fueron capturadas y trasladadas al penal del Altiplano donde en el trayecto fueron abusadas sexualmente.
Tras el desencanto de la población en los gobiernos de la derecha partidista, el PRI retoma el poder, imponiendo una serie de reformas constitucionales, entre ellas en el sector educativo (que enfrentó al magisterio disidente con el gobierno), fiscal y energético entre otras, además de la imposición de megaproyectos que generaron crispación con las poblaciones afectadas.

En plena campaña presidencial de 2012, ya como candidato del PRI a la presidencia, EPN, compareció ante los estudiantes de la Universidad Iberoamericana, quienes lo cuestionaron sobre los actos represivos de Atenco, los cuales él ordenó como gobernador del estado de México. La respuesta del candidato fue que si se volviera a presentar, lo haría de nuevo (el reprimir a los campesinos). Dicha respuesta generó rechiflas y rechazo de los estudiantes, quienes al ser tachados por su coordinador de campaña como porros, se inició un movimiento social que se gestó en las redes sociales conocido como \#Yosoy 132 (ver fig. 1) que trastocó las plazas de todas las ciudades del país, con especial acento en Ciudad de México y Guadalajara en solidaridad con los estudiantes (Olvera, 2016).

Figura 1. Cártel del movimiento \#yosoy132

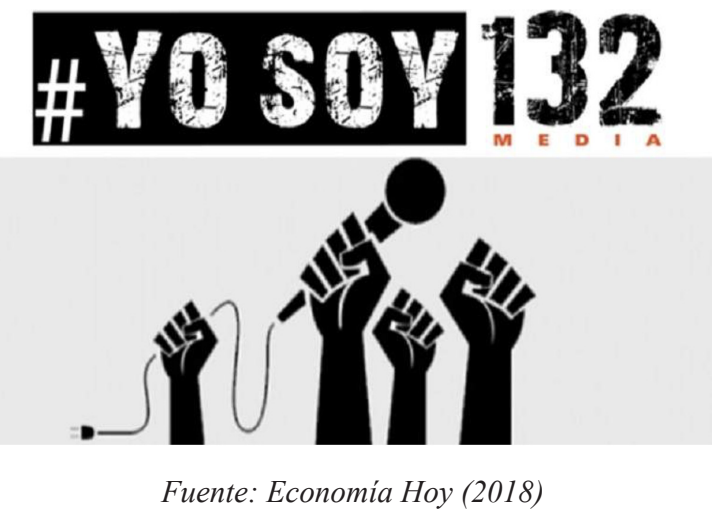

Aunado a la complicidad de la clase política en el poder y la delincuencia organizada, otro de los momentos álgidos y que generó movimientos de protesta a nivel nacional fue el caso de la ejecución de 43 estudiantes de la Normal Rural de Ayotzinapa, Guerrero, entre la noche del 26 de septiembre y la madrugada del 27 de septiembre de 2014, en uno de los estados con mayor pobreza y marginación del país, donde el gobierno federal se metió a una serie de explicaciones inverosímiles en términos de los causantes y las condiciones de 
dichas muertes (Olvera, 2016).

A la muerte de los estudiantes, se sumaron la ejecución extrajudicial de 22 delincuentes en la comunidad de Tlatlaya, Estado de México el 30 de junio de 2014; la ejecución extrajudicial de 16 personas en Apatzingán, Guerrero, el 6 de enero de 2015; los escándalos de corrupción asociados al presidente y sus principales colaboradores. Todo ello, generó hartazgo en la población que dio como resultado protestas multitudinarias a nivel nacional y el uso de la fuerza pública en algunos casos para sofocarlas o disuadirlas (Olvera, 2016).

En 2016, en Nochixtlan, Oaxaca se llevó a cabo un operativo policial en contra de profesores disidentes integrantes Coordinadora Nacional de Trabajadores de la Educación (CNTE), quienes mantenían un plantón donde exigían la derogación de la reforma educativa que privatizaba la educación y precarizaba en trabajo docente, la respuesta de las autoridades fue la represión dejando como saldo de 8 muertos, siete desaparecidos, más de 20 detenidos y torturados, y 137 personas, de los cuales 33 eran menores, "con lesiones productos de armas de fuego, balas de goma, quemaduras, golpes, fracturas e intoxicaciones" (Frente por la Libertad de Expresión y la Protesta Social (FLEPS), 2018, p. 24)

\subsubsection{Caso colombiano}

Es en el gobierno de Virgilio Barco (1986-1990) donde se empezó a implementar el modelo neoliberal, en su administración se inició el proceso de desmantelamiento del Estado benefactor con la apertura comercial apuntalada por una serie de reformas que permitió el ingreso de mercancía con bajos aranceles, fortaleciendo los intereses de las grandes corporaciones en detrimento de los productores nacionales, lo que ocasiono el cierre de fuentes de trabajos, empresas que no pudieron competir con los precios bajos de los consorcios foráneos (Martínez, 2015).

El campo colombiano se vio inmerso en la protesta colectiva a partir de las políticas neoliberales al campo, como el que pasó los días 28 y 29 de julio de 1999 con el llamado Paro Nacional Agrario convocado por la Asociación Nacional de Salvación Agropecuaria quienes exigían la condonación de las deudas de los agricultores, así como la exigencia de moderar las importaciones agrícolas que perjudicaban al productor nacional.
La represión de las autoridades no se hizo esperar donde hubo dos muertos y varios heridos (Seoane, Taddei y Algranati, 2001). De la misma manera en agosto de 2013, los campesinos colombianos se manifestaron a través de paros y bloqueos ante la exigencia de las autoridades de la obligación para los agricultores de cultivar con semillas certificadas, dejando de lado las semillas tradicionales de las comunidades. Dichas movilizaciones obligaron al gobierno reconocer a los inconformes y a negociar con ellos (Coscione y García, 2014).

En cuanto a las políticas educativas, el año 2011, en el gobierno del presidente Juan Manuel Santos, se dieron una serie de movimientos estudiantiles que protestaban contra la reforma a la Ley 30 de Educación Superior que databa de 1992, y aunque el gobierno la presentaba como la solución a los problemas educativos, pero que entre otras cosas era para impulsar la creación de "universidades con ánimo de lucro" (Acevedo y Correa, 2015, p. 47). Además, dicha ley contemplaba que los empresarios podrían invertir en las universidades públicas y un aumento gradual de los subsidios, insuficiente para las necesidades de las instituciones universitarias, el aumento de la matrícula estudiantil por medio de universidades privadas de baja calidad, sin vocación para la investigación y la innovación; y por último, evaluar de manera constante los Institutos de Educación Superior (Acevedo y Correa, 2015). Ante esto, los estudiantes exigían en las manifestaciones el derecho a la educación, en contra de los créditos para acceder a educación superior y demandando la universalidad de la educación para los jóvenes en educación superior (Galindo, Gómez y Rodríguez, 2015).

Otro de los momentos álgidos de descontento y protesta social el 21 de noviembre de 2019 bajo el gobierno de Iván Duque, a partir del llamado "paquetazo" (ver fig. 2), conocido así a las medidas de ajuste estructural que tenía como objetivo eliminar el fondo estatal de pensiones, aumentar la edad de jubilación y reducir el salario de los jóvenes por debajo del mínimo. En medio de una gran desigualdad social, amplios sectores de la población se sintieron excluidos de las políticas públicas $(B B C, 2019)$, por lo que la implementación de dichos ajustes, aunado a la decisión de reducir el impuesto a las grandes empresas y alza en las tarifas a la electricidad originó que millones de colombianos salieran a 
las calles y a las plazas públicas a protestar contra la política económica del gobierno, cuya situación fue respondida por el régimen con el uso de la fuerza policial, decretándose el toque de queda en la capital del país.

\section{Figura 2. Paro nacional contra el "paquetazo" en} Colombia

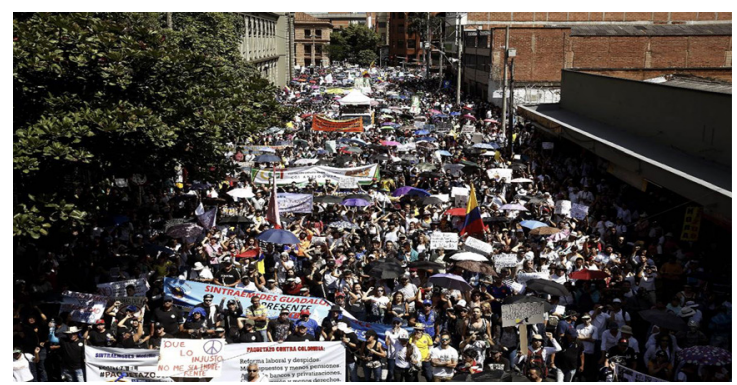

Fuente: El Universal (2019)

\subsubsection{Caso chileno}

Siguiendo la ortodoxia neoliberal promovida por los Chicago Boys, Chile es tomado como ejemplo de las políticas neoliberales en Latinoamérica, el cual fue impuesto mediante un sistema político dictatorial encabezado por Agusto Pinochet (1973-1990), que derrocó al gobierno democráticamente electo de Salvador Allende. Este país andino, aplicó dicho modelo, incluso antes que los mismos países impulsores, como EE.UU y la Gran Bretaña (Bojórquez, Ángeles y Gámez, 2020).

De acuerdo con Ffrench (2003), las reformas más importantes que se implementaron, giraron en eliminar los controles de precios, apertura comercial, privatización del sector bancario y liberalización de las tasas de interés, libertad a los flujos de capital internacional, reducción de aparato del sector público, devolución de las empresas y tierras expropiadas durante el régimen de Salvador Allende, privatización de las empresas públicas, eliminación de los derechos sindicales importantes. Dicho así, las reformas estructurales recayeron en la mayoría de la población chilena con el objetivo de imponer nuevas formas de acumulación de capital tendientes a beneficiar a los consorcios extranjeros y nacionales. Los descontentos sociales en esta etapa pinochetista fueron contenida por medio de las armas y la amenaza.

La vuelta a la democracia no significó el cambio de modelo económico, por lo que en un contexto de mayor libertad, la ciudadanía tuvo incentivos para manifestarse en torno a las políticas neoliberales. Si bien, los gobiernos de la llamada Concertación en Chile en las figuras de Ricardo Lagos (2000-2006), y Michelle Bachelet (2006-2010), tuvieron cierto éxito en inhibir la presión popular en la implementación del neoliberalismo (Navia, 2009), los problemas de las protestas públicas estallarán en el próximo presidente, Sebastián Piñera, que marcó el retorno de la derecha al poder presidencial en Chile.

Tas la llegada al poder de Piñera en diciembre de 2009, dos años transcurrieron cuando se dieron una serie de manifestaciones sociales contra la política económica. Las manifestaciones dieron inicios en el sur chileno, en la región de Magallanes debido al alza en los precios del gas natural, las cuales derivaron también en movilizaciones en el norte del país. De igual forma, se manifestaron movimientos contra el megaproyecto hidroeléctrico de Aysén, huelgas de mineros, paros laborales, reivindicaciones a favor de liberar a los presos políticos por el pueblo Mapuche y contra el despojo de sus tierras ancestrales, manifestaciones de los trabajadores del sector salud, de los afectados del terremoto, demandas a favor de la diversidad sexual, entre otros. Asimismo, el sector estudiantil irrumpió con toda su fuerza para demandar una educación gratuita y de calidad, este último movimiento de gran simpatía en la ciudadanía (Bravo, 2012).

Para el segundo ejercicio presidencial de Bachelet (2006-2010), su relación con la ciudadanía no se dio en condiciones de tersura, sobre todo el sector estudiantil que demandaba la gratuidad de la educación superior y algunas asociadas a la alimentación en los planteles educativos y la mejora en la infraestructura de escuelas. Derivado de la fuerzas de las protestas, la presidente tuvo que anunciar ante las televisoras cambios en el rubro educativo (Garretón et al., 2011) tratando de conciliar con los manifestantes.

Tras el regreso de Piñera al poder el 2018, la explosividad chilena ha ido en aumento. Las protestas detonaron el 17 de octubre de 2019 a partir del aumento en la tarifa del pasaje del sistema colectivo del Metro (ver fig. 3), lo que hizo que la gente saliera a las calles y plazas públicas a protestar y a eso se sumaron protestas en contra del sistema de pensiones, la privatización de la educación, entre otras cosas $(B B C, 2019)$, derivando en enfrentamientos 
con la policía que dio como resultado más de una veintena de muertos y cientos de heridos a mediados de noviembre.

Figura 3. Protestas populares en contra de las políticas de ajuste de Sebastian Piñera

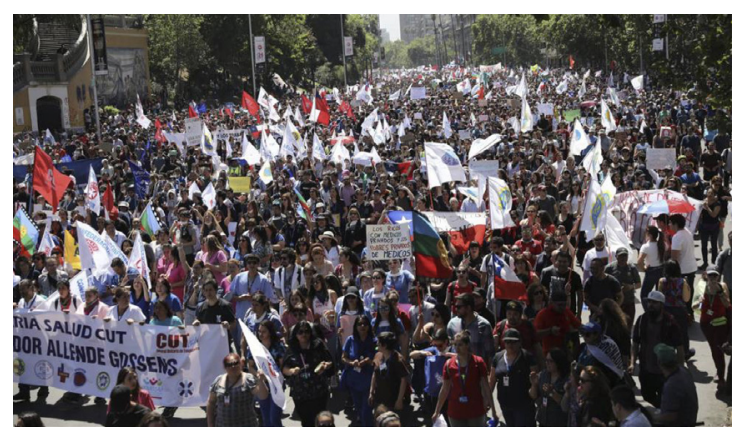

Fuente: El País (2019)

A partir de la polarización social que han generado las políticas neoliberales, tanto México, como Colombia y Chile han intentado establecer legislaciones en términos de la regulación de la protesta pública, buscando violentar derechos humanos fundamentales como la libertad de expresión y de tránsito.

\subsection{Regulación de la protesta pública en América Latina}

Los intentos por regular la protesta social en el espacio público se da en medio de campañas al llamado a la ley y el orden establecidos por los gobiernos y las élites que buscan proteger sus intereses económicos, el statu quo, sin buscar atender las causas profundas que lo han originado, en este caso, la gran desigualdad social que promueven las políticas económicas implementadas (Maqueda, 2015). A continuación exponemos los intentos de regulación de la protesta pública por los gobiernos de los países estudiados: México, Colombia y Chile.

\subsubsection{México}

En México, senadores del derechista PAN encabezadas por Mariana Gómez del Campo, presentaron el año 2013 una iniciativa llamada Ley General de Regulación de Manifestaciones Públicas, en la cual pretendían reglamentar y restringir el derecho a la protesta pública (Senado de la República, s.f). En dicha comparecencia, la senadora argumentó que la iniciativa fue elaborada junto con organizaciones de la sociedad civil (la mayoría de carácter empresarial o con nexos con dicho sector).

En este proyecto, la senadora argumentó la supuesta importancia de su iniciativa aduciendo que las marchas trastornaban la vida de las ciudades y violentaba a la ciudadanía en términos del libre tránsito a través de bloqueos y tomas de calles.

La iniciativa en su aspecto normativo (Senado de la República, 2015), de manera sintética plantea lo siguiente:

- La previsión de horarios para la realización de las marchas;

- La obligación de los organizadores para dar aviso a la autoridad sobre la realización de una marcha o manifestación, en el que se debe de dejar clara la identidad de los mismos organizadores, la fecha y hora de realización, el recorrido e itinerario;

- La posibilidad de que la autoridad modifique el recorrido por causas de orden público;

- La prohibición del uso de máscaras o el cubrirse el rostro por parte de los manifestantes, así como, de cualquier tipo de arma u objeto que pueda ser utilizado como tal.

- Un capítulo de sanciones.

DeacuerdoconeldocumentoDerechos Humanos y Protesta Social en México, que presentaron las organizaciones que conforman el Frente por la libertad de expresión y la protesta social en México (Comisión Interamericana de los Derechos Humanos, 2014), la Ley General de Regulación de Manifestaciones Públicas, consideraba sanciones por demás desproporcionadas y poca claridad para su aplicación, lo que podían dar pie a la arbitrariedad por parte de las autoridades correspondientes.

\section{2.2 Colombia}

En Colombia, derivado de las protestas sociales por las políticas de ajuste del gobierno, se impulsó en el Senado una Ley Estatutaria para Regular la Protesta Social el cual fue presentada por el legislador conservador Juan Diego Gómez, el cual establece que las manifestaciones sólo podrán ser llevadas a cabo sábados y domingos, (Radio Santa Fe, 2019).

En dicha Ley Estatutaria, en su artículo séptimo, enlista una serie de prohibiciones para quienes participen en las manifestaciones públicas (Radio Santa Fe, 2019):

a) Desarrollar la manifestación Social y 
Pacífica sin incurrir en actos de violencia o de vandalismo frente al patrimonio público, la fuerza pública, terceros y/o su patrimonio;

b) No se permitirá la presencia de encapuchados o de personas que empleen cualquier mecanismo que impida su identificación en el desarrollo de la manifestación o en los comunicados que sirvan como medio de invitación a participar en marchas;

c) No se permitirá el uso de cualquier elemento que pueda ser empleado para atentar en contra de la integridad física de los miembros de la fuerza, terceros y el patrimonio público y/o privado. $\mathrm{Su}$ uso implicará la imposición de sanciones señaladas en la presente Ley;

d) Lugares prohibidos: solo se podrá marchar o reunirse pacíficamente a una distancia de 500 metros de hospitales, centros de salud, puertos marítimos y fluviales, aeropuertos y bienes considerados como patrimonio cultural;

e) Se prohíbe la manifestación que tenga como propósito o como efecto la interrupción al acceso de trabajadores y usuarios a sus residencias o lugares de trabajo;

f) Previo a la realización de encuentros y cualquier tipo de manifestación social y pacífica, sus organizadores tienen la obligación de promover entre todos los intervinientes o los convocados, la pedagogía de la marcha pacífica y sin actos de vandalismo;

g) Garantizarán por los medios que indique el reglamento, la protección del patrimonio público y privado en todas sus formas;

h) Están prohibidos los grafitis o cualquier mecanismo para marcar, sobreponer, escribir, destruir, obstruir los bienes de carácter público y privado en ejercicio de la manifestación social en lugares no autorizados por el reglamento para el efecto;

i) Abstenerse de afectar, sabotear, dañar o destruir elementos considerados como infraestructura crítica para la provisión y prestación de bienes y servicios públicos, especialmente aquellos considerados como de servicios públicos esenciales;

j) Se garantiza la movilidad y se prohíbe la obstrucción de la vía pública de manera prolongada, esto es, por más de 10 horas o, a través de actos violentos;

Si bien, en la serie de prohibiciones de la Ley Estatutaria, se pone énfasis en no agredir o vandalizar, hay disposiciones que atentan con la libertad que todo ciudadano tiene de manifestarse libremente en protesta por la actuación de los gobernantes. Entre ellos, el sólo restringir a ciertos días (sábados y domingos), de no obstruir bienes de carácter público y privado, así como establecer lugares prohibidos para la manifestación, le quita fuerza a toda exigencia, pues las manifestaciones como medida de presión para la solución de problemas sociales, sólo tienen éxito en la medida en que dicho movimiento obliga a las autoridades a negociar bloqueando ciertos elementos claves del funcionamiento de la cotidianidad.

\subsubsection{Chile}

En Chile, aun cuando el artículo 19 de la Constitución habla del derecho que tiene todo ciudadano a reunirse de manera pacífica en el espacio público (plazas, calles, etc.), contradictoriamente afirma que las reuniones se regirán por las disposiciones de la policía. Además, y como parte de la herencia de la dictadura, se contemplan mecanismos para su autorización, donde el o los organizadores tendrán que solicitar por escrito, con sus firmas de por medio, acerca de la reunión, así como los domicilios, profesiones y números de cédula de identidad de los promoventes. Así mismo, los organizadores de la manifestación deberán de declarar el objetivo de la reunión, donde iniciará, el trayecto, quienes serán los oradores y donde terminará el evento (Marelic, 2012).

De esta manera, las manifestaciones, de acuerdo con la Constitución no deberán ser espontaneas, por lo que esta se no llevará a cabo, sino hay una organización previa del evento, y por consecuencia de no cumplir con lo marcado por la ley, esta podrá ser disuelta por las fuerzas policiacas, que en este caso descansa en el cuerpo de carabineros (Marelic, 2012).

Dichas disposiciones consagran la censura como forma de contención social, el justificante ante ello es buscar el libre tránsito, aunque en esencia representa la violación de derechos humanos innegociables como la libertad de expresión y el derecho que tiene ciudadanos independientemente de sus filias políticas, de su estatus socioeconómico, de ocupar el espacio público (Marelic, 2012), de expresarse en términos del derecho que le asiste de participar en la discusión de la vida política del país y generar contrapesos para evitar los autoritarismos. 


\section{CONCLUSIONES}

Como ha observado Simon Springer (2018), el neoliberalismo es un adversario arduo. Es por diseño amorfo, impreciso, mutante, adaptable y expansionista y, en especial difícil de definir con alguna precisión. No obstante, parece haber un entendimiento de que en su esencia se trata de la naturalización del mercado para abarcar todos los aspectos de la vida, aunque, como correctamente subraya Mirowski (2013, p. 53): "el punto de partida del neoliberalismo es la admisión, contraria a la doctrina liberal, de que su visión de la "buena sociedad tiene que ser construida; no llegará naturalmente". "De ninguna forma debe confundirse con el laissez faire: al contrario, debe verse como un llamado a la vigilancia, al activismo, a la intervención perpetua" (loc cit). Si exige, como se entrevé a lo largo de este trabajo, un reajuste del mercado (Springer, 2018), lo que conlleva la implicación de que, aunque la democracia haya sido asociada con el capitalismo, es demostrable que en su etapa neoliberal, el capitalismo también se desarrolla en regímenes semiautoritarios o autoritarios, con élites políticas y económicas que consolidan una serie de mecanismos institucionales para emitir una sucesión de disposiciones en materia económica dictadas por el dogma neoliberal en aras de la búsqueda de grandes ganancias para los consorcios del capitalismo de las elites nacionales e internacionales. Con esos entramados jurídicos, quienes detentan el poder, hacen a un lado a la mayoría de la población de la toma de decisiones en términos de las políticas laborales, medioambientales, de derechos humanos, educativas, de salud, etc., con una tendencia a minar las bases del antiguo Estado benefactor y dar una mayor amplitud de intervención a la iniciativa privada en esas áreas antes exclusivas del Estado.

Las políticas de ajuste económico neoliberal tienden a consolidar todo un marco de incertidumbre a los segmentos bajos y medios de la población, en la llamada búsqueda de la competitividad globalizadora, aumentando las horas laborales como forma de supervivencia de la clase trabajadora en un mercado laboral agresivo y sumamente explotador. En ese ambiente de imposición de las élites políticas y económicas, así como los organismos financieros internacionales, amplios segmentos de la población han salido al espacio público como una manera de visibilizar su descontento ante un modelo económico que los precariza y los victimiza a través de los medios masivos de comunicación que cubren la agenda de las élites.

En términos de respuesta política a las instituciones y prácticas del neoliberalismo, "algo está pasando a nivel global", como aseveró la revista liberal estadounidense The Nation en 2019, y está sucediendo en todas partes de manera casi simultánea alrededor del globo. Si bien en apariencias diferentes, las protestas registradas en ese año en Bolivia, el Líbano y docenas de países más (como se anota en detalle en el cuerpo de este trabajo), tienen un elemento en común. Algo sucede cuando la protesta, que abraca desde el acaudalado Londres hasta las "villas miseria" del Sur global, si bien - en apariencia - nada hay que los una. La enorme desconexión entre las perspectivas de las élites y las formas de vida y subsistencia de las masas tienen un común denominador: "Todos los países que recientemente tuvieron revueltas populares $-\mathrm{y}$ gran parte del resto del planeta - han sido regidos por décadas por un modelo económico único, en el que el "crecimiento" celebrado por las pudientes minorías ha significado la pauperización de las grandes mayorías, donde el capital fluye hacia los bolsillos europeos y estadounidenses con la misma regularidad que el drenaje fluye hacia abajo" (Ehrenreich, 2019). Se hace patente en las mentes de las mayorías que el neoliberalismo es "un método globalmente aplicable para la preservación del actual avasallador desbalance de poder" (Loc cit). Funciona microscópicamente a nivel municipal - por ejemplo, en el abandono por parte del estado del transporte público, esencial para las poblaciones de las urbes del Sur global, comparado (en Estados Unidos y varios países europeos) con el aparentemente inagotable fondo para la represión de la protesta y la "lucha contra el crimen", donde los criminales son, por supuesto, los pobres. Mientras tanto, los billonarios estacionan sus helicópteros en los techos de las grandes edificaciones de las "ciudades globales", a la vez que los multibillonarios construyen cohetes para trasladarse al espacio sideral donde, a la vez que se maravillan de sus propias hazañas, hacen planes y arman estrategias para una futura explotación de los incontables recursos de planetas y asteroides.

Ante las condiciones globales de pobreza 
generalizada para el beneficio de unos cuantos, la protesta también se generaliza. En ese ambiente de protesta social, autoridades y clase política de México, Colombia y Chile, han respondido con represión a los colectivos que salen a demandar la derogación de las políticas económicas dañinas, criminalizando a los grupos disidentes. Además de ello, se han buscado establecer mecanismos de regulación de las protestas y el espacio público, violentando el derecho que todo ser humano tiene de la libre expresión y de disentir por las políticas públicas, pretextando el alterar la paz pública y la libre circulación de automovilistas. El sentido de la regulación de la protesta social es con el objetivo de limitar el espacio público, reducirlo a ciertas áreas de las ciudades, acotando los horarios, llevar un control de quienes lideran las manifestaciones, lo cual rompe con el derecho inalienable que tiene todo individuo o grupo social en un sistema democrático de su derecho soberano de cuestionar y demandar mejores condiciones de vida. $\mathbf{C}$

\section{REFERENCIAS BIBLIOGRÁFICAS}

Acevedo, Á. y Correa, A. (2015). La movilización estudiantil universitaria del año 2011 en Colombia. Retrospectiva de un síntoma contestatario: 2011-1971. Educación y Desarrollo Social, 9(1), 40-45. https://doi.org/10.18359/reds.549

Alfaro, S., Mendoza, V. y Porras, C. (2011). Una guía para la elaboración de estudios de caso. Razón y Palabra, 75. http://www.razonypalabra.org.mx/N/N75/varia_75/01_Diaz_V75.pdf

Baigorri, A. (1995). Género y espacio. Segregación social vs. Segregación espacial. V Congreso Español de Sociología, Granada, España.

Barón, L. (2015). ¿Revolución de Facebook? Medios sociales y movimientos sociales durante la Primavera Árabe de Egipto. Trans-Pasando Fronteras, (7), 21-38.

BBC (22 de noviembre de 2019). Paro nacional en Colombia: 4 motivos detrás de las multitudinarias protestas y cacerolazos en Colombia contra el gobierno de Iván Duque. $B B C$. https://www.bbc.com/ mundo/noticias-america-latina-50503455

BBC (30 de noviembre de 2010). Nueva jornada de manifestaciones estudiantiles en el Reino Unido. $B B C$. https://www.bbc.com/mundo/noticias/2010/11/101130_manifestaciones_estudiantes_il

Berroeta, H. y Tomeu, V. (2012). La noción de espacio público y la configuración de la ciudad: fundamentos para los relatos de pérdida, civilidad y disputa. Polis, 31 .

Bojórquez, J. (2016). Patrimonio histórico y acumulación por desposesión en la ciudad turística de Cabo San Lucas, Baja California Sur, México. Revista de Ciencias Sociales, 153, 173-192. https://doi. org/10.15517/rcs.v0i153.28170

Bojórquez, J. y Ángeles, M. (2014). Expansión turística y acumulación por desposesión: el caso de Cabo San Lucas, Baja California Sur (México). Cuadernos de Geografía, 23(2), 179-202. http://dx.doi. org/10.15446/rcdg.v23n2.43452

Bojórquez, J. y Ángeles, M. (2019). Turismo y polarización social en Los Cabos, México. El proyecto Zona Dorada. Bitácora Urbano Territorial, 29(2), 117-126. https://doi.org/10.15446/bitacora. v29n2.77609

Bojórquez, J. y Ángeles, M.y Gámez,A. (2016). Espacios de Protección del Capital: panoptismo y videovigilancia en el destino turístico de Cabo San Lucas, Baja California Sur (México). ABET, 6(3), 7-20. 
Bojórquez, J., Ángeles, M. y Gámez, A. (2019). El derecho a la ciudad y rescate del espacio público en zonas urbanas turistizadas. Una reflexión para Los Cabos, Baja California Sur (México). Aposta, 80, 109-128.

Bojorquez, J., Ángeles, M. y Gámez, A. (2020). Videovigilancia y segregación espacial en tiempos del neoliberalismo autoritario. El caso de Los Cabos, Baja California Sur (México). CS, 31, 217-242. https://doi.org/10.18046/recs.i31.3668

Borja, J. (1998). Ciudadanía y espacio público. Reforma y Democracia, 12, 1-11.

Borja, J. (2011). Espacio público y derecho a la ciudad. Espacio público y derecho a la ciudad. Viento Sur, $116,39-49$.

Bravo, V. (2012). Neoliberalismo, protesta popular y transición en Chile, 1973-1989. Política y Cultura, $37,85-112$.

Bruff, I. (2014). The Rise of Authoritarian Neoliberalism. Rethinking Marxism, 26(1), 113-129. https:// doi.org/10.1080/08935696.2013.843250

Bruff, I. y Tansel, C. (2019a). Authoritarian neoliberalism: trajectories of knowledge production and praxis. Globalizations, 16(3), 233-244. https://doi.org/10.1080/14747731.2018.1502497

Bruff, I. y Tansel, C. (Eds. (2019b). Authoritarian Neoliberalism: Philosophies, Practices, Contestations. Routledge.

Calderón, F. (Coord.) (2016). La protesta social en América Latina. Editorial S.XXI.

Castro, E. (2010). El estudio de casos como metodología de investigación y su importancia en la dirección y administración de empresas. Revista Nacional de Administración, 1(2): 31-54

CELS (2016). Los Estados latinoamericanos frente a la protesta social. CELS.

CIDH (2014). Derechos Humanos y Protesta Social en México. CIDH

CNN (7 de junio de 2013). Turkey clashes: Why are Gezi Park and Taksim Square so important? CNN. https://www.bbc.com/news/world-europe-22753752

Coscione, M. y García, V. (2014). TLCs, paro nacional agrario y movimiento social en Colombia. Nuevo Mundo. Nuevos Mundos. Instituto Nacional de Ciencias Humanas y Sociales del CNRS. https://doi. org/10.4000/nuevomundo.67127

Economía Hoy (11 de mayo de 2018). Así se gestó el movimiento \#YoSoy132 hace seis años. Economía Hoy. https://www.economiahoy.mx/nacional-eAm-mx/noticias/9130475/05/18/Asi-se-gesto-elmovimiento-YoSoy132-hace-seis-anos.html

Ehrenreich, B. (2019). Welcome to the global rebellion against neoliberalism. https://www.thenation.com/ article/archive/global-rebellions-inequality/

El País (25 de octubre de 2019). Aumenta la presión de la calle en Chile con protestas más multitudinarias. El Pais. https://elpais.com/internacional/2019/10/24/actualidad/1571937300_504889.html

El Universal (21 de noviembre de 2019). Inicia paro nacional en Colombia. El Universal. https://www. eluniversal.com.mx/mundo/inicia-paro-nacional-en-colombia

Fernández, R. (2011). Política y espacio público: ciudadanía radical en manifestaciones conmemorativas. De Arquitectura, 17(24), 4-10.

Ffrench, R. (2004). Entre el neoliberalismo y el crecimiento con equidad. Tres décadas de política económica en Chile. Siglo XXI.

Frente por la Libertad de Expresión y la Protesta Social. (2018). El Sexenio de la resistencia: informe sobre la protesta social y la respuesta estatal 2012-2018. http://libertadyprotesta.org/wp-content/ uploads/2018/12/el_sexenio_de_la_resistencia_sexenio_2012-2018_fleps.pdf

Fukuyama, F. (1994). Capitalismo y democracia: el eslabón perdido. Estudios Públicos, 54, 379-393.

Galindo, C., Gómez, J. y Rodríguez, M. (2015). Repercusión del proyecto neoliberal en la educación superior en Colombia. El Ágora USB, 15(1), 73-94. https://doi.org/10.21500/16578031.3

Gamboa, P. (2003). El sentido urbano del espacio público. Bitácora Urbano Territorial, 7(1), 13-18.

Garretón, M. et al (2011). Movimiento social, nuevas formas de hacer política y enclaves autoritarios. Los debates del Consejo Asesor para la Educación en el gobierno de Michelle Bachelet en Chile. Polis, 10(30), 117-140. http://dx.doi.org/10.32735/S0718-6568/2011-N30-808

Gonzales, A. (2017). Trumpism, authoritarian neoliberalism, and subaltern latina/o politics. Aztlán, 42(2), 147-164). 
Harvey, D. (2005). A brief history of neoliberalism. Oxford University Press.

Hutchinson, Sophie (4 de junio de 2013). Social media plays major role in Turkey protests. BBC. https:// www.bbc.com/news/world-europe-22772352

Janoschka, M. y Sequera, J. (2012). Ciudadanía y espacio público en la era neoliberal. ARBOR, 188(755): 515-527. https://doi.org/10.3989/arbor.2012.755n3005

Jenss, A. (18 de octubre de 2018). Austerity urbanism goes south; authoritarian neoliberalism goes urban. $P P E . \mathrm{http} / / /$ ppesydney.net/austerity-urbanism-goes-south-authoritarian-neoliberalism-goes-urban/

Jessop, B. (2019). Authoritarian neoliberalism: periodization and critique. South Atlantic Quarterly, 118(2), 343-361.2019. https://doi.org/10.1215/00382876-7381182

Jiménez, A. (7 de septiembre de 2010). 1.100.000 personas salen a la calle en Francia contra la reforma de las pensiones según el Ministerio de Interior. El País. https://elpais.com/internacional/2010/09/07/ actualidad/1283810402_850215.html

Juego, B. (2018). Authoritarian Neoliberalism: Its ideological antecedents and Policy Manifestations from Carl Schmitt's Political Economy of Governance. Administrative Culture, 19(1), 105-136

La Jornada (25 de noviembre de 2010). La huelga general en Portugal paraliza $80 \%$ de puertos, servicios y transporte. La Jornada. https://www.jornada.com.mx/2010/11/25/economia/031n1eco

Lefebvre, H. (1970). La revolución urbana. Alianza Editorial.

Maqueda, M. (2015). La criminalización del espacio público. El imparable ascenso de las "clases peligrosas". Revista Electrónica de Ciencia Penal y Criminología, 17(13).

Marelic, B. (2012). Derechos humanos y manifestaciones públicas en Chile durante 2011: la audiencia pública ante la Comisión Interamericana de Derechos Humanos. Anuario de Derechos Humanos, (8), 173-182. DOI: 10.5354/0718-2279.2012.20574

Martínez Carazo, P. (2006). El método de estudio de caso: estrategia metodológica de la investigación científica. Pensamiento \& Gestión, (20), 165-193.

Martínez, J. (2015). Impacto de las reformas económicas neoliberales en Colombia desde 1990. In Vestigium Ire, 8(1), 78-91.

Mirón, M. (2014). Entre la casa y el ágora: género, espacio y poder en la polis griega. La Aljaba, (18), 11-33.

Monreal, P. (2016). Ciudades neoliberales: ¿el fin del espacio público? Una visión desde la Antropología urbana. Quaderns-e, 21(1), 98-112.

Navia, P. (2009). The Chilean Left: Socialist and Neoliberal. En Burdick J., Oxhorn P., Roberts K.M (Eds.). Beyond Neoliberalism in Latin America? (pp. 17-41). Palgrave Macmillan. https://doi. org/10.1057/9780230618428_2

Olvera, A. (2016). La crisis política, los movimientos sociales y el futuro de la democracia en México. Revista Mexicana de Ciencias Políticas y Sociales, 61(226), 279-29.

Ong, A. (2006). Neoliberalism as Exception. Duke University Press.

Páramo, P. y Burbano, A. (2014). Los usos y la apropiación del espacio público para el fortalecimiento de la democracia. De Arquitectura, 16, 6-15.

Priego, A. (2011). La primavera árabe: ¿una cuarta ola de democratización? UNISCI Discussion Papers, (26), 75-94.

Radio Santa Fe (12 de diciembre de 2019). Así se pretende regular la Protesta Social en Colombia; aquí el texto del proyecto de Ley Estatutaria que tramitarán en el Congreso. http://www.radiosantafe. com/2019/12/12/asi-se-pretende-regular-la-protesta-social-en-colombia-aqui-el-texto-proyectode-ley-estataturia-que-tramitaran-en-el-congreso/

Ramírez, P. (2014). La reinvención de la ciudadanía desde el espacio público en la ciudad fragmentada. Interdisciplina, 2(2): 71-96.

Ricart, N. y Remesar, A. (2013). Reflexiones sobre el espacio público. On the W@terfront, (25), 5-35.

Ryan, M. (2017). 'Authoritarian Neoliberalism': Crisis, the state, and the challenge of periodization [Tesis de Maestría, Universidad de Sidney]. https://ses.library.usyd.edu.au/handle/2123/17276

Salcedo, R. (2002). El espacio público en el debate actual: una reflexión crítica sobre el urbanismo postmoderno. Eure, 28(84), 5-19.

Salinas, A. (2015). La ola internacional de protestas 2008-2013: notas para una reflexión comparada. Encrucijadas, 9, 1-23. 
Sánchez, F. (2018). La política de la protesta en regímenes autoritarios: síntesis crítica. Sociología e Política, 26(65), 132-154. http://orcid.org/10.1590/1678-987317266506

Sartori, G. (2005). Partidos y sistemas de partidos. Marco para un análisis. Alianza.

Sato, A. (2012). Lo público del espacio. Arq, (81),17-19. http://dx.doi.org/10.4067/S071769962012000200003

Segovia, O. (2005). Espacios públicos urbanos: una contribución a la identidad y confianza social y privada. INVI, 20(55), 166-182.

Senado de la República (s.f). Proyecto de decreto por el que expide la Ley General de Regulación de Manifestaciones Públicas. https://www.senado.gob.mx/64/intervenciones/607/3215

Seoane, J., Taddei, E. y Algranati, C. (2001). Neoliberalismo, crisis y resistencias sociales en América Latina: las configuraciones de la protesta. Revista Observatorio Social de América Latina, (5), 41-52.

Springer, S. (2018). Neoliberalismo y movimiento antisistema. https://www.bbvaopenmind.com/articulos/ neoliberalismo-y-movimientos-antisistema/

Sum, N. (2019). Ordoliberal Authoritarian governance in China since 1978: world market, performance legitimacy, and biosovereign ordering. South Atlantic Quarterly, 118(2), 81-400. https://doi. org/10.1215/00382876-7381206

Szmolka, I. (2011). Democracias y autoritarismos con adjetivos: la clasificación de los países árabes dentro de una tipología general de regímenes políticos. Revista Española de Ciencia Política, (26), 11-62.

Taddei, E. (2002). Crisis económica, protesta social y 'neoliberalismo armado' en América Latina. OSAL, (7), 29-36.

Tansel, C. (2018). Authoritarian Neoliberalism and Democratic Backsliding in Turkey: Beyond the Narratives of Progress. South European Society and Politics, 23(2), 197-217. https://doi.org/10.10 80/13608746.2018.1479945

Turner, B. (2012). La ciudadanía árabe: la Primavera Árabe y sus consecuencias no intencionales. Sociología Histórica, (1), 29-53. 